\title{
The application of cumulants to flow routing
}

\author{
Renata J. Romanowicz, Joanna Doroszkiewicz \\ Institute of Geophysics, Polish Academy of Sciences, Księcia Janusza 64, 01-452 Warsaw, Poland, e-mail: \\ romanowicz@igf.edu.pl
}

\begin{abstract}
This paper aims to fill a gap between present and past research approaches to modelling flow in open channels. In particular, a history of the analytical solutions of a linearized St. Venant equation is presented. A solution of the linearized St. Venant equation, describing the response of a river channel to a single impulse forcing, the so called Instantaneous Unit Hydrograph (IUH), can be described using cumulants, defined as the moments of a logarithm of a variable. A comparison of analytical and numerical solutions of flood wave propagation under various flow conditions is given. The river reach of Biała Tarnowska is used as an illustration of both approaches. A practical application of simplified solutions to the emulator of a flood wave propagation is suggested showing a link between theory and practice.
\end{abstract}

Keywords: open channel flow, linearized St. Venant equation, analytical solutions, moments, cumulants

Submitted 24 April 2018, revised 27 June 2018, accepted 2 August 2018

\section{Introduction}

When looking through the history of research on flow routing, it is evident that there was a major change due to the development of computer technology. Namely, the continuous description of environmental processes was substituted by a discrete equivalent. In 1973, Prof. J.C.J. Dooge suggested that the continuous description should come first as more general than discrete description and relevant to physical rules governing hydrological processes (Dooge 1973). Nowadays, it is difficult to observe continuous models in the field of hydrology, however, this may change once again in the future.

The De Saint-Venant equations, SVE (Saint-Venant 1871), are nonlinear hyperbolic equations (continuous in time and space). They include the continuity equation and the momentum equation, describing the unsteady flow in rivers and open channels. They form the basis of many popular software packages (numerical discrete solvers), such as the HEC RAS and MIKE11 flow routing models (MacArthur, De Vries 1993; DHI 2003). Many users of such packages are not aware of the assumptions that must be fulfilled in order to obtain reliable results. For example, many users do not start unsteady computations from a steady state solution. Three decades ago, computer tools were not sufficiently developed to deal with complex problems and scientists were forced to look for simplified, analytical solutions of flow equations. This also forced scientists to clearly state the assumptions, helping to understand the limitations of the solutions. However, the simplified analytical solutions were rarely applied to real-life problems, mainly due to a lack of suitable data (e.g. detailed DTM of river channel and flood-plain geometry, inundation boundaries, flow and stage observations).

As the SVE cannot be solved analytically, a number of papers have presented simplified forms of the linearized SVE. These simplified SVE can be solved analytically, depending on certain assumptions. In general, the simplifications consist of neglecting some terms of the SVE momentum equation. There are three basic simplified forms of the SVE. The first is the Kinematic Wave model, which assumes that gravity and friction forces balance each other. The second is the Diffusion Wave model (also known as the convective diffusion analogy), which assumes that pressure forces are important, in addition to gravity and frictional forces (corresponding to steep slope channels with no back water effects). The last is the Dynamic Wave model (also known as the kinematic diffusion analogy), where both inertial and pressure forces are important, and backwater effects are non-negligible (mild slope channels with downstream control). The most commonly used approximations are the Kinematic Wave and Diffusion Wave routing

The first linearization of the SVE was performed independently by Deymie (1939), Masse (1939) and Dooge and Harley (1967). Both the hyperbolic and parabolic forms of the linearized SVE have been obtained (Chow et al. 1988). The linearized SVE were applied to a number of problems, including flood routing (Keefer 1974). A comparison of flood routing models originating from the linearized SVE was performed by Strupczewski and Kundzewicz (1979). 
This study aims to show a link between simplified SVE models and emulators of the distributed 1-D MIKE11 flow routing model applying the concept of Instantaneous Unit Hydrograph (IUH; Dooge 1973). Despite developments in informatics, there is still a need for simplicity and clarity to help improve the understanding of environmental processes. This study builds on research performed together with prof. Witold G. Strupczewski in the Institute of Geophysics Polish Academy of Sciences. In the following section, a short summary of research on analytical solutions of SVE will be presented, together with definitions of moments and cumulants, and their role in the derivation of the simplified models. Section 3 presents an emulator of a flow routing model based on the MIKE11 distributed model. Section 4 describes an application of an emulator using the Biała Tarnowska case study. Finally, a discussion of the results and the relevance of the approach used for the simplified analytical solutions of the SVE is presented in Section 5.

\section{Linear channel response (LCR) and cumulants}

As mentioned above, the SVE are linearized in order to derive their analytical solutions. The basic equation describing a linearized one-dimensional unsteady flow in an open channel has the form:

$\left(1-F_{0}^{2}\right) \frac{\partial^{2} Q}{\partial x^{2}}-\frac{2}{v_{0}} F_{0}^{2} \frac{\partial^{2} Q}{\partial x \delta t}-\frac{1}{g y_{0}} \frac{\partial^{2} Q}{\partial t^{2}}-\frac{2 m}{y_{0}} S_{0} \frac{\partial Q}{\partial x}-\frac{2 S_{0}}{v_{0} y_{0}} \frac{\partial Q}{\partial t}=0$

with all parameters calculated at the reference conditions, where $F_{0}$ is the Froude number; $Q$ is the perturbation of flow from the initial conditions of steady uniform flow $Q_{0}\left[\mathrm{~m}^{3} / \mathrm{s}\right] ; S_{0}$ is the bottom slope; $y_{0}$ is the hydraulic mean depth and $v_{0}$ is the mean velocity of flow. The parameter $m$ is a function of the shape of channel and the resistance law, described here by the equation:

$$
m=\frac{c_{k}}{\frac{Q_{0}}{A_{0}}}
$$

where $A_{0}$ is the cross-sectional area corresponding to the flow $Q_{0}$ and $c_{k}$ is the kinematic wave speed, as given in (Lighthill, Whitman 1955):

$$
c k=\left.\frac{d Q}{d A}\right|_{0}=-\frac{\left.\partial S_{f}\right|_{\left.\partial A\right|_{0}}}{\left.\partial S_{f}\right|_{\left.\partial Q\right|_{0}}}
$$

where $S_{f}$ is the friction slope.
Dooge and Harley (1967) applied a moment-matching diagnostic tool used in statistics to check the suitability of the simplified linear approximation to the SVE. In fact, moments were applied for the first time to hydrological data by Nash in 1959 for the identification of unit hydrograph parameters. In particular, the moments and cumulants (defined as moments of a logarithmically transformed variable) were applied to perform a systematic comparison of the simplified flow routing models and to estimate the linearization errors (Strupczewski, Dooge 1996a).

The $R^{\text {th }}$ moment about the origin of any function of time $f(t)$ (e.g. the linear channel response) is given by:

$$
M_{R}^{\prime}=\int_{0}^{\infty} f(t) t^{R} d t
$$

The generating function of moments about the origin is a Fourier transform and is widely used in statistics. The application of a one-sided Laplace transform instead of the Fourier transform is commonly applied in hydrological problems:

$$
F(s)=\int_{0}^{\infty} f(t) \exp (-t s) d t
$$

and

$$
M_{R}=\left.(-1)^{R} \frac{d^{R} F(s)}{d s^{R}}\right|_{s=0}
$$

Romanowicz et al. (1988) developed the general closed form for the $R^{\text {th }}$ cumulant of the unsteady flow wave resulting from an impulse disturbance upstream in a semi-infinite channel (without a back-water effect).

The generating function of a cumulant is defined as:

$$
G(s)=\ln [F(s)]
$$

which gives the following formula for the $R^{\text {th }}$ cumulant:

$$
C_{R}=\left.(-1)^{R} \frac{d^{R} G(s)}{d s^{R}}\right|_{s=0}
$$

It was found that the general expression for the $R^{\text {th }}$ cumulant depends on the lag of the channel, an additional three dimensionless parameters describing the channel geometry and friction in the channel, and the Froude number.

Strupczewski and Romanowicz (1991) discussed the derivation of a family of simplified models of the linearized SVE describing flow in a semi-infinite open channel. The complete linear equation (CLE) of Dooge (1973) was used as the basis for the derivation of simplified flow routing models with matching $1^{\text {st }}$ order, $1^{\text {st }}$ and $2^{\text {nd }}$ order and all three $1^{\text {st }}, 2^{\text {nd }}$ and $3^{\text {rd }}$ order cumulants of the 
full CLE. Under the assumption of $1^{\text {st }}$ cumulant equivalence, the kinematic wave model is derived. When the $1^{\text {st }}$ and $2^{\text {nd }}$ cumulants are equivalent, the simplified models have only one second order term. Among two-parameter models are the kinematic diffusion and convective diffusion analogy models. Three-parameter models include the so called Rapid Flow Model (RFM), described in detail by Strupczewski and Napiórkowski (1990). The relationship between the cumulants of a channel response and their influence on the accuracy of linear interpolation was studied by Strupczewski and Dooge (1996b) in two companion papers. The authors focused mainly on the specific characteristics of the cumulants for different Froude numbers $\left(F_{0}\right)$ within the range $[0,1]$. As the boundaries represent two limiting channel responses, the diffusion analogy for $F_{0}=0$ and the rapid flow model for $F_{0}=1$, the relationship obtained can be applied to set the initial conditions of a simplified numerical flow routing model. The RFM model was extended to the case of flow routing in a river channel with lateral (lumped) inflows by Strupczewski and Kundzewicz (1992). Moussa (1996) developed an analytical Hayami solution for diffusive wave flood routing with a uniform lateral inflow. The approach was further extended by Cholet et al. (2017) in order to solve the inverse problem of assessing lateral in-flows during floods in karst systems.

Munier et al. (2008) presented the CLE in the form of a transfer matrix in the Laplace domain. This formulation is similar to those described in studies that apply a system formulation of a flow routing problem problem (Dooge 1973) and also employs the cumulant matching approach to estimate physically-sound parameters of the derived transfer function models. The solution in the case of a non-uniform flow with a back-water effect is obtained by means of a Taylor series expansion of the elements of the Saint-Venant transfer matrix. As a result, the transfer function is approximated by a second order approximation with a delay and has the form of the first order with a delay when the second order approximation is unstable. It is interesting to note that the time-constants of the transfer function and the delay can be expressed as closedform functions of the cumulants of a transfer function for a given downstream boundary condition at a given spatial position of a channel.

\section{Application of substitution rules in flow routing - MIKE11 emulator}

The distributed 1-D MIKE11 model applies the full Saint Venant equations, which are solved using a numerical scheme (Liggett, Cunge 1975). As such, the solution may be computer-time consuming when applied to long time-horizon simulations of river flow. A distributed model emulator can be used to shorten computational time. Different types of emulators can be distinguished, depending on the classification criteria used. The emulator structure can be derived by a simplification of the basic physical equations describing the flow process, or it can be "data-driven", derived on the basis of numerical experiments (Castelletti et al. 2012).

The derivation of the emulator structure is based on the distributed model (here MIKE11) simulations, treated as a spatio-temporal interpolator. The structure depends on the input and output variables required to describe the process of interest (Romanowicz, Osuch 2011). When modelling flood risk maps, the transformation of rainfall falling on the catchment area into river water levels, at a specific river location, is determined. The customary procedure consists of the derivation of a rain-storm of the specified return period (e.g. 100 or 500-year) and treating it as an input to the system, including rainfallrunoff and flow-routing models. The risk maps derived for the areas located along the river reach are treated as floodinundation maps of the same return period as a return period of a design storm applied at the system input. This chain of actions makes the unrealistic assumption that both rainfall-runoff and flow routing models are linear. The simulation approach allows for the linearity assumption to be avoided (Romanowicz, Kiczko 2016). However, this approach requires multiple runs of the flow routing model, which can be computer-time demanding. The emulators can be used to overcome this (Doroszkiewicz, Romanowicz 2018). As mentioned, it is possible to derive several different emulators for the flow routing. Possible options include a diffusion analogy model Nash cascade (Nash 1959), or a transfer function approach, including nonlinear transfer functions with the delay (Litrico et al. 2010). In this paper, a stochastic transfer function (STF) model (Young 1998) is applied as an emulator of MIKE11 due to its direct correspondence to IUH and a numerical convenience.

\section{Examples - Biala Tarnowska case study}

The River Biała Tarnowska is used as a case study (Fig. 1). The mountainous Biała Tarnowska catchment is located in southern Poland, with an area of about $967 \mathrm{~km}^{2}$. In this study, the flow routing was limited to the reach between the Ciężkowice and Koszyce gauging stations, in the lower part of the catchment. There are a number of ungauged tributaries present that substantially influence the flow volumes at Koszyce. They were 


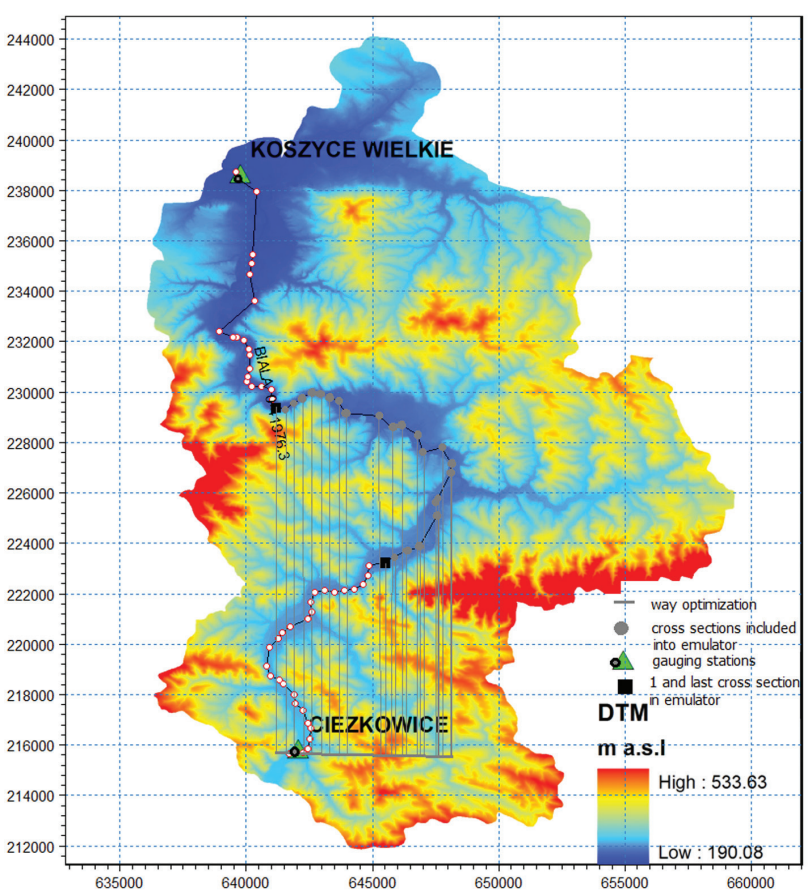

Fig. 1. Study area of the Ciężkowice-Koszyce flow routing model, the Tuchów meander is located between black squares

taken into account in the MIKE11 model in the form of both uniform lateral and lumped flows. The flows of these ungauged tributaries were estimated using geographical information (subcatchment area) and the differences between flow volumes at Ciężkowice and Koszyce. The procedure is described in detail by Doroszkiewicz and Romanowicz (2018). When predictions are the main aim of the modelling, the hydrological model for upper and the whole catchments should be used to simulate flow (Doroszkiewicz, Romanowicz 2018). The precipitation-rainfall HBV model based on Lindstrom et al. (1997) was applied for flow simulations in this study. The upper catchment with a gauging station at Ciężkowice has an area of $527 \mathrm{~km}^{2}$. Also shown in Figure 1 is the Tuchów meander, used to illustrate the correspondence between emulator characteristics and an analytical solution.

The hydraulic model MIKE11 of the Ciężkowice - Koszyce Wielkie reach of the River Biała Tarnowska has 118 cross sections specified using the triple zone approach. The triple zone approach defines the resistance, represented by model roughness coefficients, in each cross section. Model roughness coefficients were optimized using the Nash-Sutcliff goodness of fit criterion (NSE) for flows (Nash, Sutcliffe 1970). The calibration stage produced an NSE equal to 0.8 , whilst at the validation stage, the NSE was equal to 0.77 .

The applied emulator has a flow-flow structure, with the rating curve transforming flows into the water levels at each of the MIKE11 cross-sections. The structure of the emulator for the Ciężkowice-Koszyce reach is presented in Figure 2.

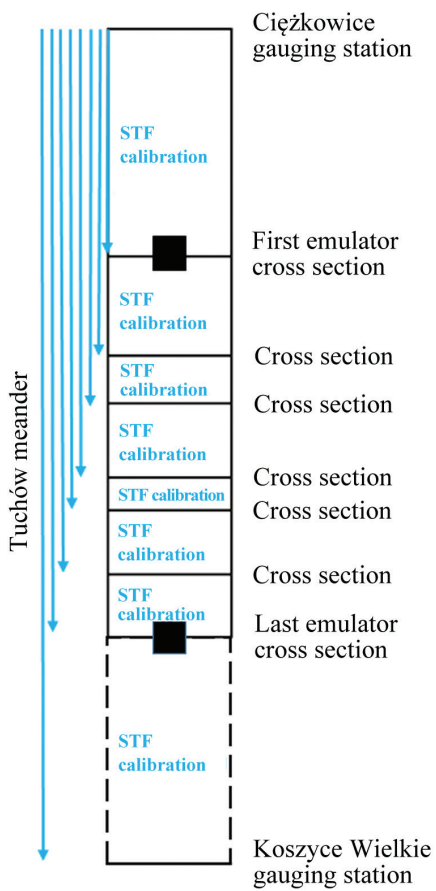

Fig. 2. Lumped-parameter emulator for the flow routing model for the Ciężkowice-Koszyce reach

Many different lumped parameter flow routing models can be used within the emulator structure. In this study we propose a simple flow-flow Stochastic Transfer Function (STF) model (Young 1998):

$$
y_{n, k}=\frac{R_{n}}{\left(1-P_{n} z^{-1}\right)} x_{k-\delta}+\varepsilon_{k}
$$

where $y_{n, k}$ denotes flows at the $n^{\text {th }}$ MIKE11 cross-section; $x_{k-\delta}$ denotes the inflow at the Ciężkowice gauging station; $\delta$ denotes pure advective delay and $R_{n}$ and $P_{n}$ are the STF model parameters; $k=\Delta t, \ldots, K \cdot \Delta t$ denotes the time instant, $\Delta t=1$ hours, $\varepsilon_{k}=N(0, \sigma)$.

The model presented above has a linear structure. The emulator parameters are derived using the simulated flow at Ciężkowice as input variables and the MIKE11 flow evaluated at each of the cross-sections as the observed output variable. The number of emulator modules is equal to the number of cross-sections. There is a total of 118 models for the whole Ciężkowice-Koszyce reach. The emulator parameters $P_{n}$ and $R_{n}$ represent the residence times $T_{n}$ and gain $G_{n}$ of the river reach following the formulae:

$$
\begin{gathered}
T_{n}=-\ln \left(\frac{1}{P_{n}}\right)+\delta_{n} \\
G_{n}=\frac{R_{n}}{1-P_{n}}
\end{gathered}
$$


Table 1. Selected MIKE11 emulator residence time, gain and NSE values for the Tuchów meander

\begin{tabular}{|c|c|c|c|}
\hline $\begin{array}{c}\text { Distance } \mathrm{x} \\
{[\mathrm{km}]}\end{array}$ & $\begin{array}{c}T_{n} \\
{[\mathrm{~h}]}\end{array}$ & $G_{n}$ & $\begin{array}{c}\text { NSE } \\
{[\%]}\end{array}$ \\
\hline 2 & 4.8 & 1.20 & 84 \\
\hline 4 & 5.6 & 1.24 & 85 \\
\hline 6 & 6.2 & 1.25 & 86 \\
\hline 8 & 6.6 & 1.25 & 86 \\
\hline 10 & 7.3 & 1.26 & 86 \\
\hline 12 & 8.4 & 1.30 & 86 \\
\hline 13.6 & 8.9 & 1.30 & 86 \\
\hline 14.4 & 9.0 & 1.31 & 86 \\
\hline
\end{tabular}

The emulator with the first order transfer functions represents the kinematic wave model and is directly related to the IUH (Dooge 1973). The second order model is equivalent to the diffusion analogy model. The spatial distribution of the model parameters is achieved through the emulator model structure, based on the MIKE11 crosssections. The gain parameter $G_{n}$ presents the information on the lateral inflow, i.e., the amount of water added or subtracted along the specified reach $n$.

The derived emulator residence times, gain and the NSE values for the Tuchów meander reach (Fig. 1) are given in Table 1.

The parameters in Table 1 vary depending on the distance from the input in Ciężkowice, with residence times increasing with distance. The dependence of the gain on distance is caused by the lateral inflows, which are introduced into the MIKE11 model. These parameters also depend on the magnitude of the input flow (Romanowicz et al. 2008), controlled by the process of non-linearity. The goodness of fit criterion is high (84-86), indicating a nearly linear MIKE11 performance for average flows.

The dependence of the residence times on distance from the upstream Tuchów meander cross-section is presented in Figure 3. That dependence is consistent with the results of the Lag and Route model of Munier et al. (2008), where a transfer function model was developed for coupling the rainfall-runoff model with flow routing in order to support reservoir releases upstream of the modelled reach. As presented in the latter publication, the transfer function parameters can be directly related to the first three cumulants of the Saint-Venant transfer function.

\section{Discussion and conclusions}

This study aimed to show a link between the analytical solutions of the SVE and numerical solutions of a flowrouting problem. The major advantage of the application

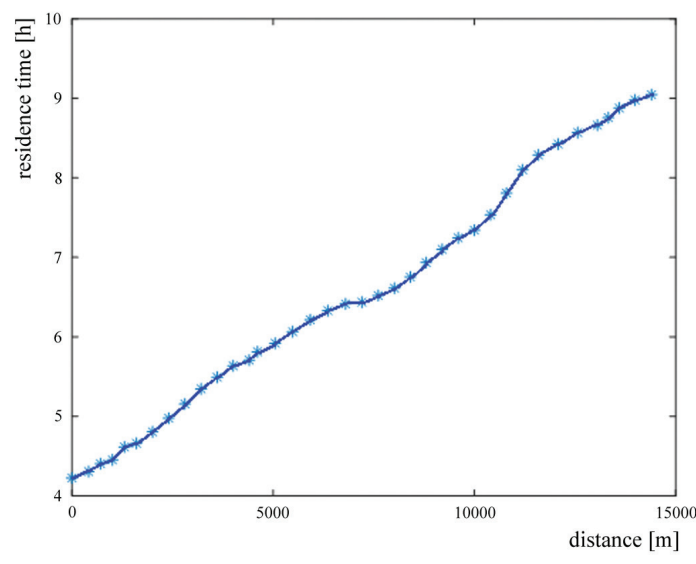

Fig. 3. Dependence of residence time on the distance from the upstream cross-section for the Tuchów meander reach of the River Biała Tarnowska; stars denote cross-section positions along the reach

of analytical solutions lies in the clear specification of the assumptions applied. Unfortunately, these assumptions are almost never met in practice. Numerical solutions present answers without listing the assumptions required, yet they do not provide any estimates of the solution's reliability, unless a thorough statistical analysis of the model predictions is performed (Romanowicz et al. 1996). A distributed model emulator is introduced to fill the gap between the analytical simplified flow routing solutions and a fully numerical distributed model. The emulator parameters are compared to the simplified SVE solution presented in Munier et al. (2008), taking into account the backwater effect and lateral inflows. The results show that emulators are able to describe the flow routing process in a physically justified manner.

\section{Acknowledgement}

This work was partially supported within the statutory activities No 3841/E-41/S/2017 of the Ministry of Science and Higher Education of Poland.

\section{Bibliography}

Castelletti A., Galelli S., Restelli M., Soncini-Sessa R., 2012, Data-driven dynamic emulation modelling for the optimal management of environmental systems, Environmental Modelling and Software 34, 30-43, DOI: 10.1016/j.envsoft.2011.09.003

Cholet C., Charlier J.-B., Moussa R., Steinmann M., Denimal S., 2017, Assessing lateral flows and solute transport during floods in a conduit-flow-dominated karst system using the inverse problem for the advection-diffusion equation, Hydrology and Earth System Sciences, 21 (7), 3635-3653, DOI: 10.5194/hess-21-3635-2017 
Chow V.T., Maidment D.R., Mays L.W., 1988, Applied hydrology, McGraw Hill, 572 pp.

Deymie P., 1939, Propagation d'une intumescence allongee, [in:] Procceddings of Fifth International Congress on Applied Mechanics, Verlag John Wiley \& Sons, 537-544

DHI, 2003, MIKE 11 - A modeling system for river and channels: user guide?, DHI Water \& Environment, avaiable at https://www.tu-braunschweig.de/Medien-DB/geooekologie/ mike11usersmanual.pdf (data access 03.09.2018)

Dooge J.C.I., 1973, Linear theory of hydrological systems, Agricultural Research Service, U.S. Department of Agriculture, $327 \mathrm{pp}$.

Dooge J.C.I., Harley B.M., 1967, Linear routing in uniform open channels, [in:] Proceedings of the International Symposium in Hydrology, Fort Collins, Colorado, USA, 1, 57-63

Doroszkiewicz J., Romanowicz R.J., 2018, An influence of flow projection errors on flood hazard in future climate conditions, submitted for publication to Natural Hazards

Keefer T.N., 1974, Desktop computer flow routing, Journal of the Hydraulics Division, 100 (7) 1047-1058

Liggett J.A., Cunge J.A., 1975, Numerical methods of solution of the unsteady flow equations, [in:] Unsteady flow in open channels, vol. 2, K. Mahmood, V. Yevjevich (eds.), Water Resources Publications

Lighthill M., Whitman G., 1955, On kinematic waves: I. Flood movement in long rivers, Proceedings of the Royal Society A: Mathematical, Physical and Engineering Sciences, 229 (1178), 281-316, DOI: 10.1098/rspa.1955.0088

Lindström G., Johansson B., Persson M., Gardelin M., Bergström S., 1997, Development and test of the distributed HBV-96 hydrological model, Journal of Hydrology, 201 (1-4), 272-288, DOI: 10.1016/S0022-1694(97)00041-3

Litrico X., Pomet J.-B., Guinot V., 2010, Simplified nonlinear modelling of river flow routing, Advances in Water Resources, 33 (9), 1015-1023, DOI: 10.1016/j.advwatres.2010.06.00

MacArthur R., Devries J.J., 1993, Introduction and application of kinematic wave pouting techniques using HEC-1, TD-10, US Army Corps of Engineers, available at http://www.hec. usace.army.mil/publications/TrainingDocuments/TD-10.pdf (data access 02.08.2018)

Masse P.R., 1939, Recherches sur la teorie des eaux courantes, [in:] Proceedings of the Fifth International Congress on Applied Mechanics, New York, 545-549

Moussa R., 1996, Analytical Hayami solution for the diffusive wave flood routing problem with lateral inflow, Hydrological Processes, 10 (9), 1209-1227, DOI: 10.1002/(SICI)10991085(199609)10:9<1209::AID-HYP380>3.0.CO;2-2

Munier S., Lerat G., Belaud J., Litrico X., 2008, A new compact model coupling rainfall-runoff and routing model to support reservoir releases management, $13^{\text {th }}$ IWRA World Water Congree, Montpellier, France, 16 pp.

Nash J.E., 1959, Systematic determination of unit hydrograph parameters, Journal of Geophysical Research, 64 (1), 111115, DOI: 10.1029/JZ064i001p00111

Nash J.E., Sutcliffe J.V., 1970, River flow forecasting through conceptual models. Part I - A discussion of principles, Journal of Hydrology, 10 (3), 282-290, DOI: 10.1016/00221694(70)90255-6

Romanowicz R.J., Beven K.J., Tawn J., 1996, Bayesian calibration of flood inundation models, [in:] Floodplain Processes, M.G. Anderson, D.E. Walling (eds.), Wiley, Chester, 333-360

Romanowicz R.J., Dooge J.C.I., Kundzewicz Z., 1988, Moments and cumulants of linearized St. Venant equation, Advances in Water Resources, 11 (2), 92-100, DOI: 10.1016/03091708(88)90042-5

Romanowicz R.J., Kiczko A., 2016, An event simulation approach to the assessment of flood level frequencies: risk maps for the Warsaw reach of the River Vistula, Hydrological Processes, 30 (14), 2451-2462, DOI: 10.1002/hyp.10857

Romanowicz R.J., Osuch M., 2011, Assessment of land use and water management induced changes in flow regime of the Upper Narew, Physics and Chemistry of the Earth. Parts A/B/C, 36 (13), 662-672, DOI: 10.1016/j.pce.2011.04.012

Romanowicz R.J., Young P.C., Beven K., Pappenberger F., 2008, A data based mechanistic approach to nonlinear flood routing and adaptive flood level forecasting, Advances in Water Resources, 31 (8), 1048-1056, DOI: 10.1016/j.advwatres.2008.04.015

Saint-Venant A., 1871, Theorie du mouvement non permanent des eaux, avec application aux crues des rivieres et a 1 introduction de marees dans leurs lits, Comptes rendus de l'Academie des Sciences, 73, 147-154 and 237-240

Strupczewski W.G., Dooge J.C.I., 1996a, Relationships between higher cumulants of channel response. I: Properties of the linear channel response, Hydrological Sciences Journal, 40 (6), 675-687, DOI: 10.1080/02626669509491458

Strupczewski W.G., Dooge J.C.I., 1996b, Relationships between higher cumulants of channel response. II: Accuracy of linear interpolation, Hydrological Sciences Journal, 41 (1), 61-73, DOI: $10.1080 / 02626669609491479$

Strupczewski W.G., Kundzewicz Z., 1979, Analysis of physical interpretation of parameters of linear conceptual models by means of moment matching method, J. Hydrol. Sci, 6, 143-159

Strupczewski W.G., Kundzewicz Z.W., 1992, Rapid flow model with lateral inflow, Hydrology Research, 23 (2), 57-72, DOI: 10.2166/nh.1992.0005 
Strupczewski W.G., Napiórkowski J.J., 1990, Linear flood routing model for rapid flow, Hydrological Sciences Journal, 35 (1), 49-64, DOI: 10.1080/02626669009492404

Strupczewski W.G., Romanowicz R.J., 1991, Invariance of the IUH first cumulants of simplified linear St. Venant models, Advance in Water Resources, 14 (4), 175-182, DOI: 10.1016/0309-1708(91)90013-E
Young P., 1998, Data-based mechanistic modelling of environmental, ecological, economic and engineering systems, Environmental Modelling and Software, 13 (2), 105-122, DOI: 10.1016/S1364-8152(98)00011-5 